\title{
Effects of phosphorus enrichment on the spatial heterogeneity of stream periphyton under uneven light conditions
}

\author{
Alessandra Iannino $(\mathbb{D} \cdot$ Alexander Tim Ludwig Vosshage $\cdot$ Markus Weitere • \\ Patrick Fink
}

Received: 23 October 2020/Revised: 12 February 2021/Accepted: 16 April 2021/Published online: 5 May 2021

(C) The Author(s) 2021

\begin{abstract}
Spatial variations in light and nutrient availability usually lead to a heterogeneous distribution of periphyton biomass within streams, but the effects of nutrient enrichment on periphyton heterogeneity are still poorly understood. We tested phosphorus enrichment effects on the heterogeneity of periphyton quantity and nutritional quality in an environment with uneven light conditions. Natural periphyton was grown at either high or low $\mathrm{P}$ supply in circular running water flumes, each of which was half shaded and half in light. After 3 weeks, periphyton biomass was significantly more heterogeneous at high
\end{abstract}

Handling editor: Judit Padisák

Supplementary Information The online version contains supplementary material available at https://doi.org/10.1007/ s10750-021-04591-0.

A. Iannino $(\bowtie) \cdot$ P. Fink

Workgroup Aquatic Chemical Ecology, University of Cologne, Zülpicherstrasse 47b, 50674 Cologne, Germany e-mail: alessandra.iannino@ufz.de

A. Iannino - A. T. L. Vosshage - M. Weitere - P. Fink Department of River Ecology, Helmholtz Centre for Environmental Research - UFZ, Brückstrasse 3a,

39114 Magdeburg, Germany

P. Fink

Department of Aquatic Ecosystem Analysis and Management, Helmholtz Centre for Environmental Research - UFZ, Brückstrasse 3a, 39114 Magdeburg, Germany
$\mathrm{P}$ than at low $\mathrm{P}$ supply, as algal production increased with light only in the P-enriched treatment. However, periphyton C:P ratio was equally homogeneous in both $\mathrm{P}$ treatments, despite the light differences within each experimental flume. Although this outcome seems to contrast with the light:nutrient hypothesis, it is likely that high-quantity periphyton patches acquired more $\mathrm{P}$ and depleted the available $\mathrm{P}$ for the low-quantity patches, leading to an even $\mathrm{C}: \mathrm{P}$ ratio within each flume. Therefore, in an environment with heterogeneous light availability, nutrient enrichment has the potential to increase the heterogeneity of periphyton quantity without affecting the heterogeneity of periphyton quality, due to periphyton patches not being independent of one another.

Keywords Spatial heterogeneity - Light:nutrient hypothesis · Eutrophication - Stoichiometry · Fatty acids $\cdot$ Periphyton $\cdot$ Algae $\cdot$ Stream

\section{Introduction}

Light and nutrients are the main abiotic factors that limit the growth of autotrophic periphyton in stream ecosystems (Rosemond, 1993; Warren et al., 2017). While periphyton quantity increases with both light and nutrient availability, periphyton nutritional quality for herbivores is usually enhanced by a balance between light and nutrients. Periphyton quality is 
often quantified as algal content of phosphorus $(\mathrm{P})$ and nitrogen $(\mathrm{N})$ relative to carbon $(\mathrm{C})$, i.e. $\mathrm{C}: \mathrm{P}$ and $\mathrm{C}: \mathrm{N}$ stoichiometric ratios (Stelzer \& Lamberti, 2002; Fink \& von Elert, 2006). As a general rule, periphyton relative content of nutrients decreases as the ratio of light to nutrient availability increases, consistent with the light:nutrient hypothesis (Sterner et al., 1997; Fanta et al., 2010; Hill et al., 2011). A similar outcome has also been observed with periphyton relative content of polyunsaturated fatty acids (PUFA; Hill et al., 2011), another major determinant of algal food quality for grazers (Guo et al., 2016; Twining et al., 2016). Algal PUFA content increases with P availability, as P is needed for the biosynthesis of PUFArich phospholipids and galactolipids, but high-light availability dilutes algal PUFA content while $\mathrm{C}$ is accumulated (Hill et al., 2011).

As natural streams are highly heterogeneous systems (Palmer \& Poff, 1997), light and nutrient availability can vary considerably within the same stream, even on small spatial scales (Warren et al., 2017). This variability can lead to a high degree of heterogeneity of both periphyton biomass and nutritional quality for grazers. The spatial heterogeneity of periphyton is a critical factor in regulating biotic interactions, nutrient cycling and foodweb processes (Stevenson, 1997; Hillebrand, 2008; Winemiller et al., 2010). However, while most research has focused on the heterogeneity of periphyton quantity (Winemiller et al., 2010), very few studies so far have investigated how the heterogeneity of periphyton quality is affected by variations in abiotic factors. Yet, the heterogeneity of periphyton nutritional quality may play an important role in shaping community dynamics, as grazers are likely to be attracted to, and therefore, aggregate on high-quality food patches in a heterogeneous environment (Moelzner \& Fink, 2015), and their uneven distribution may further enhance the heterogeneity of the whole system.

In a previous experiment (Iannino et al., 2019), we observed that, after a grazing period, periphyton biomass was more heterogeneously distributed in phosphorus-poor flumes than in phosphorus-rich flumes. We speculated that nutrient enrichment might have homogenised the relative $\mathrm{P}$ content of periphyton, leading to a more uniform grazer distribution in the P-enriched flumes. Excessive nutrient inputs into streams are a severe and widespread environmental issue that commonly leads to eutrophication, with harmful consequences for water quality and biodiversity (Dodds \& Smith, 2016; Wurtsbaugh et al., 2019). Although the effects of nutrient enrichment on periphyton quantity and quality have been widely studied (e.g. Hillebrand \& Kahlert, 2001; Hill et al., 2011; Cashman et al., 2013; Iannino et al., 2020), consequences for the spatial heterogeneity of periphyton are still poorly understood. At low-to-moderate nutrient concentrations, variations in light availability within a stream are likely to result in a highly heterogeneous periphyton nutritional quality for grazers; as nutrient concentrations increase, algae might become nutrient saturated and, thus, exhibit a uniformly high nutrient content relative to carbon regardless of light availability.

In this study, we investigated how phosphorus enrichment would affect the heterogeneity of both periphyton quantity and quality, denoted as variability in periphyton biomass and nutrient content at the patch scale for grazers, in a system with heterogeneous light conditions. We grew natural periphyton at either high or low P availability in circular half-shaded flumes. The following hypotheses were tested: (1) heterogeneous light conditions within the flumes would lead to a heterogeneous distribution of periphyton biomass, with higher biomass in areas of higher light intensity, at both high and low $\mathrm{P}$ supply, but (2) periphyton nutritional quality, both in terms of C:P stoichiometry and PUFA content relative to $\mathrm{C}$, would be more heterogeneous in P-poor than P-rich systems under heterogeneous light conditions, due to nutrient saturation at elevated $\mathrm{P}$ availability.

\section{Materials and methods}

\section{Experimental set-up and procedure}

Each experimental unit consisted of a circular flume in a $22 \times 27 \mathrm{~cm}$ (height $\times$ diameter) plastic bucket with a small pump in the centre, generating a circular water current. On the bottom surface of each flume were nine $5 \times 5 \mathrm{~cm}$ slots for tiles. Half of the total surface of each flume (including the top opening) was covered with a shading net sunscreen fabric, which reduced incoming irradiance (measured as photosynthetically active radiation, PAR) by $60 \%$. The average PAR intensity above the flumes, produced by LED lamps, was $38.59 \mu \mathrm{mol} \mathrm{m} \mathrm{m}^{-2} \mathrm{~s}^{-1}$ in the non-shaded half and 
$15.5 \mu \mathrm{mol} \mathrm{m} \mathrm{m}^{-2} \mathrm{~s}^{-1}$ in the shaded half of the flumes, measured at the water surface.

The experiment consisted of two treatments: low $\mathrm{P}$ availability $\left(15 \mu \mathrm{g} \mathrm{P}^{-1}, \mathrm{P}-\right)$ and high $\mathrm{P}$ availability (100 $\mu \mathrm{g} \mathrm{P}^{-1}, \mathrm{P}+$ ), to mimic oligotrophic and eutrophic conditions, respectively (Dodds \& Smith, 2016). Each flume was filled with 61 modified WC medium (Guillard \& Lorenzen, 1972; Iannino et al., 2020) diluted in tap water (1:15) with an adjusted $P$ concentration according to the respective treatment. The average water current velocity in the flumes was $14 \mathrm{~cm} \mathrm{~s}^{-1}$. Each treatment was replicated five times, resulting in a total of ten half-shaded flumes. The flumes were placed in a row on a shelf in a climate chamber at $20 \pm 1{ }^{\circ} \mathrm{C}$ with a 16:8 h light:dark cycle. The water temperature in the flumes was approximately $2{ }^{\circ} \mathrm{C}$ higher than the room temperature, due to the heat generated by the pumps.

Natural periphyton was collected in the River Agger in western Germany ( $50^{\circ} 56^{\prime} 12.4^{\prime \prime} \mathrm{N}, 7^{\circ} 17^{\prime}$ $37.1^{\prime \prime} \mathrm{E}$ ) and inoculated in a concrete outdoor pool at the University of Cologne in June 2019. The pool was filled with 1501 diluted (1:15) WC medium (Guillard \& Lorenzen, 1972; Iannino et al., 2020) with an adjusted $\mathrm{P}$ concentration of $15 \mu \mathrm{g}^{-1}$ and was covered with mesh to prevent leaf litter and animals from entering. The pool's bottom surface was covered with $4.7 \times 4.7 \mathrm{~cm}$ unglazed ceramic tiles, as substrate for periphyton growth. Three days after inoculation, when a thin periphyton layer covered the tiles, two periphyton-covered tiles were placed in each experimental flume, i.e. one in the shaded half and one in the nonshaded half. Additionally, three periphyton-covered tiles were randomly selected to analyse initial stoichiometry, fatty acid and taxonomic composition of periphyton. For this, periphyton was scraped off each tile and homogenised with $40 \mathrm{ml}$ tap water. Aliquots from each suspension were filtered onto pre-combusted glass fibre filters (Whatman GF/F, $25 \mathrm{~mm} \varnothing$ ) for elemental and fatty acid analyses (see following sections), and $1 \mathrm{ml}$ of each suspension was mixed with $100 \mu \mathrm{l}$ Lugol's iodine solution for microscopic counts under an inverted microscope.

Periphyton was allowed to grow in the flumes for 21 days. The water in the flumes was replaced every 6 days with fresh nutrient medium according to the respective treatment. Each flume was shifted by one position to the right every 2 days, to ensure equal average light intensity in all flumes and exclude position effects. The experiment ended on 15 July 2019, 3 days after the last medium replacement. Periphyton was scraped off each tile and suspended in $100 \mathrm{ml}$ tap water, of which aliquots were filtered onto pre-combusted GF/F filters for elemental and fatty acid analyses. In addition, $1 \mathrm{ml}$ of each suspension was mixed with $100 \mu$ Lugol's iodine solution for microscopic counts under an inverted microscope, to identify the algal groups present in the flumes and determine periphyton taxonomic composition.

\section{$\mathrm{C}: \mathrm{P}$ stoichiometry analysis}

For $\mathrm{C}$ analysis, filters were dried at $60^{\circ} \mathrm{C}$ for $48 \mathrm{~h}$, packed in tin capsules (HekaTech, Wegberg, Germany) and analysed with a Thermo Flash EA2000 Analyser (Schwerte, Germany). For P analysis, filters were placed in a solution of potassium peroxodisulphate and $1.5 \%$ sodium hydroxide, and autoclaved at $120{ }^{\circ} \mathrm{C}$ for $1 \mathrm{~h}$. Periphyton $\mathrm{P}$ was subsequently analysed with the molybdate-ascorbic acid method (Greenberg et al., 1985) with a DR5000 UV-Vis spectrophotometer (Hach, Düsseldorf, Germany).

Fatty acid analysis

For fatty acid extraction and analysis, each filter was transferred into $5 \mathrm{ml}$ extraction solvent $\left(\mathrm{CH}_{2} \mathrm{Cl}_{2} /\right.$ $\mathrm{MeOH}, 2: 1)$ and stored at $-20{ }^{\circ} \mathrm{C}$. Subsequently, $10 \mu \mathrm{g}$ heptadecanoic acid methyl ester $\left(\mathrm{C}_{17: 0} \mathrm{ME}\right)$ and $10 \mu \mathrm{g}$ tricosanoic acid methyl ester $\left(\mathrm{C}_{23: 0} \mathrm{ME}\right)$ were added to each sample as internal standards. Samples were then placed in an ultrasound bath for $3 \mathrm{~min}$ and centrifuged at $4,500 \times g$ for $5 \mathrm{~min}$. The supernatants were dried at $40{ }^{\circ} \mathrm{C}$ under a stream of nitrogen gas, and $5 \mathrm{ml} 3 \mathrm{~N}$ methanolic $\mathrm{HCl}$ was added to each sample. The samples were incubated at $70{ }^{\circ} \mathrm{C}$ for $20 \mathrm{~min}$, and $6 \mathrm{ml}$ isohexane was added to each sample. The upper phases were dried at $40{ }^{\circ} \mathrm{C}$ under a nitrogen stream and redissolved in $100 \mu \mathrm{l}$ isohexane.

The fatty acid composition of the samples was determined via gas chromatography with a 6890 N GC System (Agilent Technologies, Waldbronn, Germany) equipped with a DB-225 capillary column (30 m, $0.25 \mathrm{~mm}$ i.d., $0.25 \mu \mathrm{m}$ film thickness, J\&W Scientific, Folsom, CA, USA) and a flame ionisation detector. For instrument settings, see Iannino et al. (2020). Quantification of fatty acids was performed for each sample by referring to the internal standards and 
previously established calibration functions for each fatty acid.

Heterogeneity analysis

The heterogeneity of periphyton biomass, C:P stoichiometry, and PUFA content for each flume was measured with a coefficient of variation $(\mathrm{CV})$, i.e. the ratio of standard deviation to the mean. $\mathrm{CV}$ is a basic, yet straightforward method to describe variability within a system and, therefore, has been widely used in periphyton studies (e.g. Liess \& Hillebrand, 2004; Peters et al., 2007; Hillebrand, 2008; Iannino et al., 2019). Although CV only gives a simple measure of overall variation and ignores dependence on spatial distance, we believe that it was suitable for our smallscale experiment, in which spatially explicit data were not relevant.

\section{Data analysis}

All data were checked and approved for normal distribution with a Shapiro-Wilk's test and for homoscedasticity with a Levene's test. Two-sample $t$-tests were used to compare coefficients of variation (CV) of periphyton biomass, C:P, and PUFA content. In addition, interactive effects of $\mathrm{P}$ availability and light on periphyton biomass, C:P ratio, PUFA content, and chlorophyte abundance were determined with two-factor repeated measures analyses of variance (ANOVAs) with light as nested within-subjects factor, followed by post hoc multiple pairwise comparisons with a Bonferroni correction. Statistical analyses were performed in R ( $\mathrm{R}$ Core Team, version 3.6.1, 2019).

\section{Results}

Periphyton initial conditions

At the beginning of the experiment, periphyton was mainly composed of chlorophytes $(98 \pm 1.1 \%$, mean \pm s.d.), with a small proportion of diatoms ( $2 \pm 1.13 \%$, Table 2 in Supplementary Material). No other algal classes were observed. The initial average periphyton biomass was $1.56 \pm 0.28 \mathrm{mg}$ particulate organic carbon (POC) per tile. Periphyton average molar C:P ratio was 293:1, and the average relative
PUFA content was $17.93 \pm 1.6 \mu \mathrm{g} \mathrm{mg} \mathrm{C}^{-1}$ (Table 2 in Supplementary Material).

Periphyton heterogeneity

At the end of the experiment, periphyton biomass was significantly more heterogeneous at high $\mathrm{P}(\mathrm{P}+)$ than at low $\mathrm{P}$ availability $(\mathrm{P}-$ ) (two-sample $t$-test; $t=3.28$, df $=8, P=0.011$; Fig. 1a), whereas the $\mathrm{CV}$ of both periphyton $\mathrm{C}: \mathrm{P}$ ratio and PUFA content did not differ between the $\mathrm{P}+$ and $\mathrm{P}-$ treatments (two-sample $t$ test; C:P ratio: $t=-0.26, \mathrm{df}=8, P=0.8$, Fig. $1 \mathrm{~b}$; PUFA content: $t=0.89$, df $=8, P=0.4$, Fig. 1c).

Light intensity had a significant effect on periphyton biomass and significantly interacted with $\mathrm{P}$ availability in determining periphyton biomass (Table 1), which was significantly higher under high light intensity in the $\mathrm{P}+$ treatment (Fig. 2a). P availability had a significant effect on periphyton $\mathrm{C}: \mathrm{P}$ stoichiometry, but it did not significantly interact with light, which had no effect (Table 1). Periphyton C:P ratio was significantly higher in the $\mathrm{P}-$ than in the $\mathrm{P}+$ treatment, but it did not differ between high light and low light conditions (Fig. 2b). The interaction between $P$ availability and light significantly affected periphyton PUFA content (Table 1), which was significantly higher under high light in the

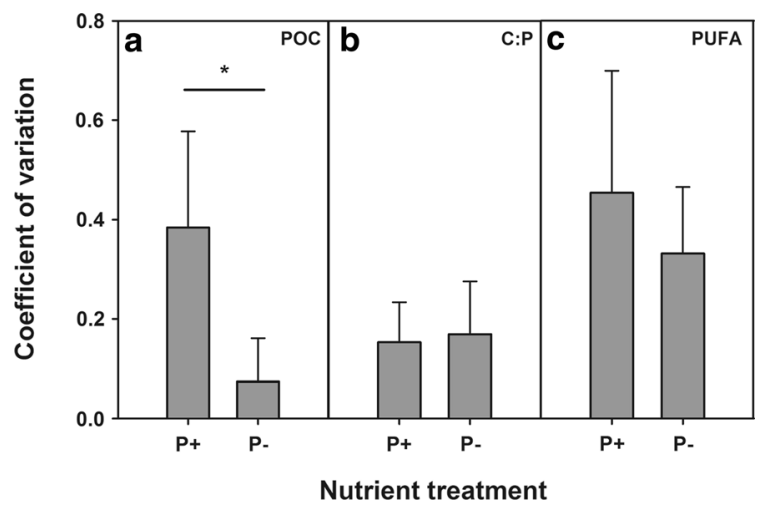

Fig. 1 Coefficient of variation (CV), used as a measure of heterogeneity, of periphyton biomass as particulate organic carbon (POC, a), molar C:P ratio (b) and relative content of polyunsaturated fatty acids (PUFA, c) at high $\mathrm{P}(\mathrm{P}+)$ and low $\mathrm{P}$ supply $(\mathrm{P}-)$. Values are mean $\pm \mathrm{SD}$ of $n=5$ replicate tiles. The asterisk indicates a significant difference between the two $P$ treatments for the $\mathrm{CV}$ of periphyton biomass $(P=0.011)$. No significant difference was detected for the $\mathrm{CV}$ of periphyton $\mathrm{C}: \mathrm{P}$ ratio $(P=0.8)$ nor for the $\mathrm{CV}$ of periphyton PUFA content $(P=0.4)$ 
Table 1 Results of two-factor repeated measures ANOVAs on the effects of phosphorus and light on periphyton biomass as particulate organic carbon (POC), periphyton C:P ratio, periphyton content of polyunsaturated fatty acids (PUFA), and periphyton chlorophyte percentage

\begin{tabular}{|c|c|c|c|c|c|c|c|c|c|}
\hline & \multirow[t]{2}{*}{$\mathrm{df}$} & \multicolumn{2}{|l|}{ POC } & \multicolumn{2}{|l|}{$\mathrm{C}: \mathrm{P}$} & \multicolumn{2}{|c|}{ PUFA } & \multicolumn{2}{|c|}{ Chlorophyte \% } \\
\hline & & $F$ & $P$ & $F$ & $P$ & $F$ & $P$ & $F$ & $P$ \\
\hline \multicolumn{10}{|l|}{ Between subjects } \\
\hline Phosphorus & 1 & 1.98 & 0.19 & 28.42 & $<0.001$ & 6.59 & $\mathbf{0 . 0 3}$ & 0.12 & 0.74 \\
\hline \multicolumn{10}{|l|}{ Within subjects } \\
\hline Light & 1 & 23.16 & 0.001 & 0.13 & 0.73 & 8.95 & 0.02 & 0.06 & 0.81 \\
\hline Phosphorus $\times$ Light & 1 & 24.24 & 0.001 & 0.17 & 0.69 & 6.03 & 0.04 & 3.26 & 0.11 \\
\hline
\end{tabular}

Significant effects $(P<0.05)$ are highlighted in bold
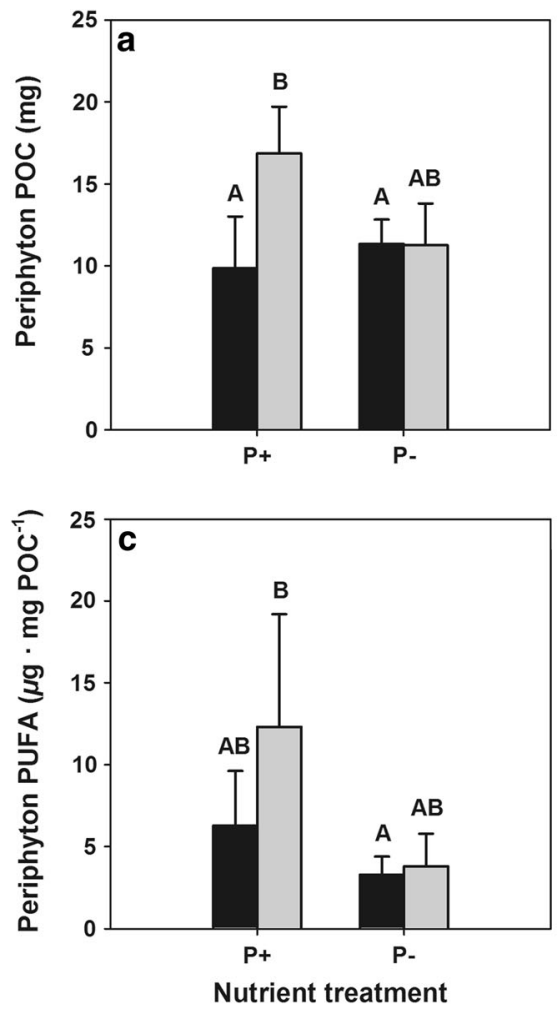

Fig. 2 Periphyton biomass expressed as particulate organic carbon per tile (POC, a), molar C:P ratio (b) and relative content of polyunsaturated fatty acids (PUFA, c) at high $\mathrm{P}(\mathrm{P}+)$ and low $\mathrm{P}$ supply $(\mathrm{P}-)$, in high light (grey bars) and low light (black

$\mathrm{P}+$ treatment than under low light in the $\mathrm{P}$ - treatment, while no significant differences in PUFA content were observed between high light and low light intensity within any of the $\mathrm{P}$ treatments (Fig. 2c).

Periphyton was mainly composed of chlorophytes $(>96 \%)$ in all treatments, with a small percentage of

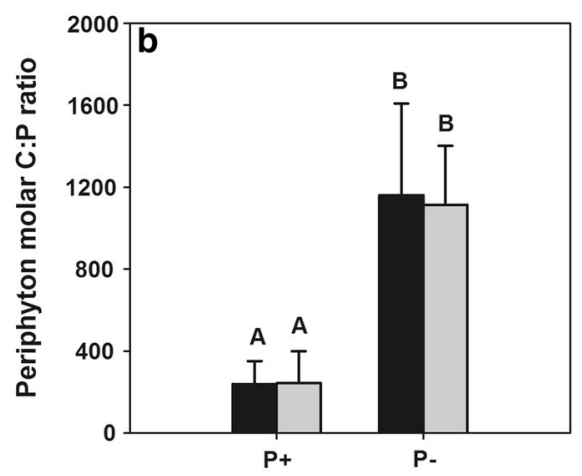

Nutrient treatment

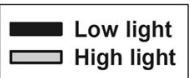

bars). Values are mean \pm SD of $n=5$ replicate tiles. Different letters indicate significant differences between treatments, indicated by multiple pairwise comparisons with a Bonferroni correction

diatoms ( $<4 \%$; Table 3 in Supplementary Material). $\mathrm{P}$ availability and light had no significant effects on the taxonomic composition of periphyton, measured as chlorophyte abundance (Table 1). 


\section{Discussion}

Contrary to our expectations, in a system with heterogeneous light conditions, periphyton biomass was more heterogeneously distributed under $\mathrm{P}$ enrichment than under $\mathrm{P}$ deficiency. In the P-enriched flumes, the heterogeneous light availability interacted with $\mathrm{P}$ addition and resulted in a significantly higher periphyton biomass in the illuminated half of the flume compared to the shaded half, in which periphyton growth was apparently light limited. In the P-depleted flumes, however, periphyton biomass was homogeneously distributed, i.e. equally low between the differently illuminated areas, which suggests a primary $\mathrm{P}$ limitation of periphyton growth. However, even though high light availability increased biomass production in the P-enriched treatment, this increase did not translate into a higher C:P ratio. Unexpectedly, algal C:P ratio was homogeneous between periphyton patches under different light conditions, at both high and low $\mathrm{P}$ availability. While $\mathrm{P}$ enrichment significantly increased periphyton relative $\mathrm{P}$ content, light had no effects on periphyton C:P ratio, which only differed between the two nutrient treatments and not between the differentially illuminated areas. At first sight, these results may seem to contrast with the light:nutrient hypothesis, which states that periphyton $\mathrm{C}: \mathrm{P}$ ratio should increase together with the ratio of light to nutrient availability (Sterner et al., 1997). However, most studies that found patterns consistent with the light:nutrient hypothesis were full-factorial experiments, in which every experimental unit was independent and assigned to a given set of homogeneous conditions, i.e. either completely shaded or completely in the light (Elser et al., 2003; Dickman et al., 2006; Hill et al., 2011). In our experimental design, the illuminated and shaded areas were not independent of one another but were part of the same heterogeneous environment. Therefore, in the P-enriched flumes, in which periphyton biomass was more abundant under high light than under low light, the available dissolved $\mathrm{P}$ was absorbed by the periphyton patches in proportion to their biomass, resulting in a homogeneous $\mathrm{C}: \mathrm{P}$ ratio even if periphyton biomass was heterogeneously distributed.

The light levels in the experimental flumes were lower than what is normally considered as high light availability in natural streams (Warren et al., 2017). However, the difference in light intensity within each flume was strong enough to cause a significant increase in periphyton biomass in the non-shaded half of the flume, at least at high phosphorus supply. Furthermore, an increase in algal C:P ratios driven by light has been observed in fully factorial experiments under light levels similar to those in our flumes (Dickman et al., 2006; Hill et al., 2011), whereas light intensity at higher values, comparable to natural light levels, failed to have an effect on algal C:P ratios in previous tests of the light:nutrient hypothesis in which different light treatments were close to one another within the same flumes and not independent of one another (Hill \& Fanta, 2008; Hill et al., 2009). In such cases, periphyton patches may also have absorbed phosphorus in proportion to their biomass, resulting in a lack of light effects even at high irradiances. Therefore, in the present study, the lack of light effects on periphyton C:P ratios were arguably due to the non-independence of the different light environments, rather than the moderate light levels.

Interestingly, periphyton PUFA relative content was equally heterogeneous in P-enriched and P-poor flumes. Both $\mathrm{P}$ availability and light had significant effects on periphyton PUFA content, yet only the PUFA content of periphyton in the illuminated half of P-enriched flumes was significantly higher than the PUFA content in the shaded half of P-poor flumes, suggesting a colimitation by $\mathrm{P}$ supply and light. Several other studies have shown that $\mathrm{P}$ enrichment increases PUFA production in algae (Guschina \& Harwood, 2006; Hill et al., 2011; Guo et al., 2016), whereas high irradiance has been observed to decrease algal PUFA content due to photoacclimation and oxidative damage (Guschina \& Harwood, 2006, 2009). However, the light availability in our flumes was likely below saturating levels and still within the range needed for algal PUFA biosynthesis, thus it did not result in lower periphyton PUFA content.

The difference in nutrient availability between treatments did not affect the community composition of periphyton, unlike in a previous, similar experiment in which we investigated the effects of $\mathrm{P}$ supply on periphyton structure (Iannino et al., 2020). In this previous experiment, diatoms dominated the periphytic community at low $\mathrm{P}$ supply, whereas $\mathrm{P}$ enrichment led to a significant increase in the proportion of chlorophytes and cyanobacteria. As different algal groups exhibit different stoichiometry and fatty 
acid profiles (Quigg et al., 2003; Taipale et al., 2013), such a taxonomic shift eventually resulted in higher periphyton $\mathrm{C}: \mathrm{P}$ ratios and lower PUFA relative content. In the present study, on the other hand, periphyton was mainly composed of chlorophytes in all treatments, both at the beginning and at the end of the experiment; hence, phosphorus enrichment was associated with lower periphyton C:P ratios and higher PUFA content. This discrepancy is due to differences in periphyton collection and manipulation methods before the start of each experiment. In the first study, natural periphyton was collected in the Rhine, a large river where diatoms are the predominant algal group (Ackermann et al., 2011) and inoculated into the experimental flumes on the same day of collection; in the present study, periphyton was collected in the much smaller river Agger and pre-grown for three days in an outdoor pool during summer, thus, establishing a homogeneous periphytic community dominated by chlorophytes that was subsequently used in the experiment. Therefore, as the taxonomic composition of periphyton did not change throughout the experiment, $\mathrm{P}$ enrichment decreased the $\mathrm{C}: \mathrm{P}$ ratio and increased the PUFA content of periphyton. Nevertheless, if the starting periphytic community had been composed of diatoms, $\mathrm{P}$ enrichment may have caused an algal taxonomic shift that would have likely affected the differences in periphyton $\mathrm{C}: \mathrm{P}$ ratio and PUFA content between the two nutrient treatments.

Our results shed more light on the effects of nutrient enrichment and light on periphyton heterogeneity in streams. As streams are highly heterogeneous environments (Palmer \& Poff, 1997), periphyton patches under different light conditions may occur in close proximity within the same stream, without being independent of one another as in a fully factorial experiment. Therefore, variations in light and nutrient availability will influence the spatial distribution of stream periphyton biomass and nutrient content in a more complex way than that predicted by the light:nutrient hypothesis. This study shows for the first time that, in an environment with heterogeneous light conditions, periphyton biomass may be more heterogeneously distributed at high $\mathrm{P}$ than at low $\mathrm{P}$ availability, but despite this, periphyton nutritional quality may remain homogeneous, because periphyton patches with a higher biomass will acquire more nutrients than periphyton with low biomass. In such a scenario, periphyton quantity more than quality has the potential to lead to an uneven distribution of grazers, which may, nevertheless, increase the heterogeneity of periphyton quality through an uneven nutrient regeneration mediated by excretion (Liess \& Hillebrand, 2004).

Overall, in an ecosystem with a homogeneously low background nutrient availability, nutrient enrichment may not reduce the spatial heterogeneity of periphyton. However, further studies should investigate how eutrophication may affect periphyton heterogeneity in streams with a heterogeneous nutrient availability, owing to, e.g. biogeochemical hotspots (McClain et al., 2003) and/or hydrogeological variations (Valett et al., 1997). In such cases, periphyton quality will be heterogeneous under normal conditions, and external nutrient enrichment is more likely to homogenise the nutrient content of periphyton. Furthermore, variations in light and nutrient availability in streams are likely to interact with variations in water current velocity, which will add a further level of complexity to the heterogeneity of periphyton quantity and quality. High water current alters periphyton biomass and composition, and increases periphyton nutrient uptake (Hiatt et al., 2019; Risse-Buhl et al., 2020). Nevertheless, it is important to remember that different environments in nature are often not independent of one another but may instead interact with one another in unexpected ways. In heterogeneous ecosystems, interacting factors may have complex, counter-intuitive outcomes, not always in accordance with theoretical models such as the light:nutrient hypothesis.

Acknowledgements We would like to thank Carolyn Ewins for help with the experiment and Anna Herzog for assistance with $\mathrm{C}$ analysis. This study was supported by the Deutsche Forschungsgemeinschaft (DFG), Grant FI 1548/7-1 to Patrick Fink and WE 3545/9-1 to Markus Weitere.

Author contributions AI, PF and MW designed the experiment; AI conducted the experiment and collected the data; AI, PF and ATLV analysed the data; AI wrote the manuscript; PF, ATLV and MW edited the manuscript.

Funding Open Access funding enabled and organized by Projekt DEAL.

Data availability The datasets generated and analysed during the current study are available from the corresponding author on reasonable request.

Code availability Not applicable. 


\section{Declarations}

Conflict of interest The authors declare no conflict of interest.

Open Access This article is licensed under a Creative Commons Attribution 4.0 International License, which permits use, sharing, adaptation, distribution and reproduction in any medium or format, as long as you give appropriate credit to the original author(s) and the source, provide a link to the Creative Commons licence, and indicate if changes were made. The images or other third party material in this article are included in the article's Creative Commons licence, unless indicated otherwise in a credit line to the material. If material is not included in the article's Creative Commons licence and your intended use is not permitted by statutory regulation or exceeds the permitted use, you will need to obtain permission directly from the copyright holder. To view a copy of this licence, visit http://creativecommons.org/licenses/by/4.0/.

\section{References}

Ackermann, B., M. Esser, A. Scherwass \& H. Arndt, 2011. Long-term dynamics of microbial biofilm communities of the River Rhine with special references to ciliates. International Review of Hydrobiology 96: 1-19.

Cashman, M. J., J. D. Wehr \& K. Truhn, 2013. Elevated light and nutrients alter the nutritional quality of stream periphyton. Freshwater Biology 58: 1447-1457.

Dickman, E. M., M. J. Vanni \& M. J. Horgan, 2006. Interactive effects of light and nutrients on phytoplankton stoichiometry. Oecologia 149: 676-689.

Dodds, W. K. \& V. H. Smith, 2016. Nitrogen, phosphorus, and eutrophication in streams. Inland Waters 6: 155-164.

Elser, J. J., M. Kyle, W. Makino, T. Yoshida \& J. Urabe, 2003. Ecological stoichiometry in the microbial food web: a test of the light:nutrient hypothesis. Aquatic Microbial Ecology 31: 49-65.

Fanta, S. E., W. R. Hill, T. B. Smith \& B. J. Roberts, 2010. Applying the light:nutrient hypothesis to stream periphyton. Freshwater Biology 55: 931-940.

Fink, P. \& E. Von Elert, 2006. Physiological responses to stoichiometric constraints: nutrient limitation and compensatory feeding in a freshwater snail. Oikos 115: 484-494.

Greenberg, A. E., R. R. Trussel \& L. S. Clesceri, 1985. Standard Methods for the Examination of Water and Wastewater. American Public Health Association (APHA), Washington, DC.

Guillard, R. R. L. \& C. J. Lorenzen, 1972. Yellow-green algae with chlorophyllide $c$. Journal of Phycology 8: 10-14.

Guschina, I. A. \& J. L. Harwood, 2006. Lipids and lipid metabolism in eukaryotic algae. Progress in Lipid Research 45: 160-186.

Guschina, I. A. \& J. L. Harwood, 2009. Algal lipids and effect of the environment on their biochemistry. In Kainz, M., M. Brett \& M. Arts (eds), Lipids in Aquatic Ecosystems. Springer, New York: 1-24.
Guo, F., M. J. Kainz, F. Sheldon \& S. E. Bunn, 2016. Effects of light and nutrients on periphyton and the fatty acid composition and somatic growth of invertebrate grazers in subtropical streams. Oecologia 181: 449-462.

Hiatt, D. L., J. A. Back \& R. S. King, 2019. Effects of stream velocity and phosphorus concentrations on alkaline phosphatase activity and carbon:phosphorus ratios in periphyton. Hydrobiologia 826: 173-182.

Hill, W. R. \& S. E. Fanta, 2008. Phosphorus and light colimit periphyton growth at subsaturating irradiances. Freshwater Biology 53: 215-225.

Hill, W. R., S. E. Fanta \& B. J. Roberts, 2009. Quantifying phosphorus and light effects in stream algae. Limnology and Oceanography 54: 368-380.

Hill, W. R., J. Rinchard \& S. Czesny, 2011. Light, nutrients and the fatty acid composition of stream periphyton. Freshwater Biology 56: 1825-1836.

Hillebrand, H., 2008. Grazing regulates the spatial variability of periphyton biomass. Ecology 89: 165-173.

Hillebrand, H. \& M. Kahlert, 2001. Effect of grazing and nutrient supply on periphyton biomass and nutrient stoichiometry in habitats of different productivity. Limnology and Oceanography 46: 1881-1898.

Iannino, A., A. T. L. Vosshage, M. Weitere \& P. Fink, 2019. High nutrient availability leads to weaker top-down control of stream periphyton: compensatory feeding in Ancylus fluviatilis. Freshwater Biology 64: 37-45.

Iannino, A., A. T. L. Vosshage, M. Weitere \& P. Fink, 2020. Taxonomic shift over a phosphorus gradient affects the stoichiometry and fatty acid composition of stream periphyton. Journal of Phycology 56: 1687-1695.

Liess, A. \& H. Hillebrand, 2004. Invited review: direct and indirect effects in herbivore-periphyton interactions. Archiv für Hydrobiologie 159: 433-453.

McClain, M. E., E. W. Boyer, C. L. Dent, S. E. Gergel, N. B. Grimm, P. M. Groffman, S. C. Hart, J. W. Harvey, C. A. Johnston, E. Mayorga, W. H. McDowell \& G. Pinay, 2003. Biogeochemical hot spots and hot moments at the interface of terrestrial and aquatic ecosystems. Ecosystems 6: 301-312.

Moelzner, J. \& P. Fink, 2015. Consumer patchiness explained by volatile infochemicals in a freshwater ecosystem. Ecosphere 6: 35 .

Palmer, M. A. \& N. L. Poff, 1997. The influence of environmental heterogeneity on patterns and processes in streams. Journal of the North American Benthological Society 16: 169-173.

Peters, L., H. Hillebrand \& W. Traunspurger, 2007. Spatial variation of grazer effects on epilithic meiofauna and algae. Journal of the North American Benthological Society 26: 78-91.

Quigg, A., Z. V. Finkel, A. J. Irwin, Y. Rosenthal, T. Y. Ho, J. R. Reinfelder, O. Schofield, F. M. M. Morel \& P. G. Falkowski, 2003. The evolutionary inheritance of elemental stoichiometry in marine phytoplankton. Nature 425: 291-294.

Risse-Buhl, U., C. Anlanger, A. Chatzinotas, C. Noss, A. Lorke $\&$ M. Weitere, 2020. Near streambed flow shapes microbial guilds within and across trophic levels in fluvial biofilms. Limnology and Oceanography 65: 2261-2277. 
Rosemond, A. D., 1993. Interactions among irradiance, nutrients, and herbivores constrain a stream algal community. Oecologia 94 (4):585-594

Stelzer, R. S. \& G. A. Lamberti, 2002. Ecological stoichiometry in running waters: periphyton chemical composition and snail growth. Ecology 83: 1039-1051.

Sterner, R. W., J. J. Elser, E. I. Fee, S. J. Guildford \& T. H. Chrzanowsi, 1997. The light:nutrient ratio in lakes: the balance of energy and materials affects ecosystem structure and process. American Naturalist 150: 663-684.

Stevenson, R. J., 1997. Scale-dependent determinants and consequences of benthic algal heterogeneity. Journal of the North American Benthological Society 16: 248-262.

Taipale, S. J., U. Strandberg, E. Peltomaa, A. W. E. Galloway, A. Ojala \& M. T. Brett, 2013. Fatty acid composition as biomarkers of freshwater microalgae: analysis of 37 strains of microalgae in 22 genera and in seven classes. Aquatic Microbial Ecology 71: 165-178.

Twining, C. W., J. T. Brenna, N. G. Hairston, \& A. S. Flecker, 2016. Highly unsaturated fatty acids in nature: what we know and what we need to learn. Oikos 125: 749-760.
Valett, H. M., C. N. Dahm, M. E. Campana, J. A. Morrice, M. A. Baker \& C. S. Fellows, 1997. Hydrologic influences on groundwater-surface water ecotones: heterogeneity in nutrient composition and retention. Journal of the North American Benthological Society 16: 239-247.

Warren, D. R., S. M. Collins, E. M. Purvis, M. J. Kaylor \& A. Bechtold, 2017. Spatial variability in light yields colimitation of primary production by both light and nutrients in a forested stream ecosystem. Ecosystems 20: 198-210.

Winemiller, K. O., A. S. Flecker \& D. J. Hoeinghaus, 2010. Patch dynamics and environmental heterogeneity in lotic ecosystems. Journal of the North American Benthological Society 29: 84-89.

Wurtsbaugh, W. A., H. W. Paerl \& W. K. Dodds, 2019. Nutrients, eutrophication and harmful algal blooms along the freshwater to marine continuum. WIREs Water 6: e1373.

Publisher's Note Springer Nature remains neutral with regard to jurisdictional claims in published maps and institutional affiliations. 